Lexis Vol. XLIV (2) 2020: 745-786

\title{
Ontología del tiempo y problemas identitarios desde el ciberpunk/steampunk español: dos muestras
}

\author{
José Antonio Calzón García \\ Universidad de Cantabria
}

\section{RESUMEN}

El artículo analiza el tratamiento de las ideas de tiempo e identidad en dos obras de la ciencia ficción española adscritas, en mayor o menor medida, a los subgéneros del steampunk y del ciberpunk: El mapa del tiempo de Félix J. Palma y Lágrimas en la lluvia de Rosa Montero, respectivamente. El objetivo, una vez repasados los conceptos teóricos fundamentales, es analizar de forma contrastiva las dos novelas, comprobando cómo los universos paralelos y los mundos virtuales constituyen herramientas narrativas que permiten conformar distintas metáforas en torno al tiempo y a la idea de yo a fin de propiciar la reflexión filosófica en el lector.

Palabras clave: steampunk, ciberpunk, ciencia ficción, identidad

The Ontology of Time and Identity Troubles from Spanish Cyberpunk/Steampunk: Two Examples

\begin{abstract}
The article analyses the treatment of the ideas of time and identity in two Spanish science fiction novels which belong, to a greater or lesser degree, to the subgenres of steampunk or cyberpunk: El mapa del tiempo, by Félix
\end{abstract}

https://doi.org/10.18800/lexis.202002.010 
J. Palma, and Lágrimas en la lluvia, by Rosa Montero. Once the main theoretical concepts are exposed, the target is to analyse contrastly both novels, by verifying how parallel universes and virtual worlds are used as narrative strategies to create several metaphors on the ideas of time and selfness in order to go in depth in the philosophical reflection in the reader. Keywords: Steampunk, cyberpunk, science fiction, identity

1. Introducción: ciencia ficción y ontologías alternativas. Tiempos y espacios paralelos

\subsection{La ciencia ficción. El caso español}

Sustentada con frecuencia a partir de "una innovación científica o tecnológica [...] que no tiene por qué ajustarse a la realidad posible" (Hesles Sánchez 2013: 76), la ciencia ficción, tradicionalmente, ha arrancado desde la idea "de que las cosas podrían haber sido diferentes; que este es uno de los muchos mundos posibles; que, si vienes a este mundo desde otro planeta, este sería un mundo de ciencia ficción” (Barceló 2009: 31). En otras palabras, la ciencia ficción, desde esta lectura, plantearía un universo alternativo - pasado, presente o futuro- en el cual determinados avances científicos posibilitaron un devenir diferente al mundo tal y como hoy lo conocemos. No obstante, lo cierto es que, hoy en día, la science fiction es contemplada desde una perspectiva mucho más rica, con lo que "ha dejado de considerarse un género escapista para pasar a convertirse en un terreno de la imaginación desde el cual se toma distancia para permitir observar, recrear y hasta criticar la realidad" (Guhl 2001: 52), desarrollando un "pacto de ficción" que emana de las propias características del género (Moreno Serrano 2010: 68 y 73), y que lleva al lector a aceptar como improbable una historia donde algo resquebraja la realidad (Sánchez y Gallego 2003) desde el momento en el que se rompe la dinámica de una lectura más o menos automática (Moreno Serrano 2010: 83 y 110). Todo ello lleva, en suma, a un modelo de narrativa en el que se busca una evidente pátina de 
realismo que no renuncia ni a lo plausible ni a lo verosímil (Moreno Serrano 2010: 84-86, 97 y 103). Así, si bien el delectare es una condición irrenunciable de la narrativa, la ciencia ficción tendría, por encima de todo, un componente especulativo y crítico de donde surge un modelo de historia que busca, en última instancia, la reflexión en torno a la sociedad (Palardy 2018: 6; Díez 2008) a partir de una "sensación de desasosiego" (Moreno Serrano 2013: 11) que no nos abandona durante el proceso de lectura.

¿Cómo definir, pues, la ciencia ficción? Renunciando a explicaciones un tanto reduccionistas, como la de Grilli Silva (2016:138), quien se centra fundamentalmente en los componentes distópicos o tecnológicos, podríamos asumir, con Moreno Serrano (2010: 106), que la ciencia ficción es "toda aquella forma literaria cuyo rasgo dominante es la presencia de cambios establecidos por la inclusión de elementos no existentes en nuestra realidad inmediata, pero considerados posibles"; en otras palabras, una "ficción proyectiva [esto es, no realista] basada en elementos no sobrenaturales" (Moreno Serrano 2010: 106), donde nos enfrentamos a historias de imposible localización "en el mundo que conocemos, debido a una transformación del escenario narrativo [...], pero de tal modo que lo relatado es aceptable como especulación racional” (Sánchez y Gallego 2003).

Respecto a la historia del género, lo cierto es que, si bien es posible rastrear el origen de la ciencia ficción en el Frankenstein (1818) de Mary Shelley (López-Pellisa 2018b: 9), no será hasta bien entrado el siglo XIX, con autores como Julio Verne o Herbert G. Wells, cuando cierta narrativa comience a adquirir un "aire de familia" que justificará su adscripción al género de los denominados, entre otras fórmulas, scientific romances. ${ }^{1}$ Sin embargo, habrá que esperar hasta los años 30 del pasado siglo para que la expresión science fiction se acuñe $e^{2}$ para designar a un tipo muy específico de narración cercano

\footnotetext{
1 No obstante, como apunta Martín Rodríguez (2018: 85), en el caso español este tipo de narrativa se denominó a menudo "novela utópica".

2 En efecto, la expresión science fiction, usada ya por William Wilson en 1851 (LópezPellisa 2018b: 10), comenzará a extender su uso hacia 1930, siendo Hugo Gernsback el primero en definirla en 1926: "por cientificción quiero decir el tipo de historia que
} 
a determinados patrones localizables en autores como Poe, Verne o Wells, el cual poco después adquirirá naturaleza de subcategoría narrativa: "John W. Campbelll, editor de la revista Amazing Stories, logró la definición en los años cuarenta para todo el género literario, la science fiction" (Hesles Sánchez 2013: 63-64).

En el caso particular de la ciencia ficción española, ${ }^{3}$ el enorme peso de la tradición realista en nuestras letras (Martín Rodríguez 2013: 66), acaudillada por Menéndez Pidal, ${ }^{4}$ parece haber condicionado no tanto la producción ${ }^{5}$ como la recepción académica, al menos hasta no hace mucho. ${ }^{6}$ En cualquier caso, el mundo académico, que nunca llegó a estar del todo a espaldas de la ciencia

escribían Julio Verne, H. G. Wells y Edgar Allan Poe, una mezcla romántica de hechos científicos y visión profética” (López-Pellisa 2018b: 10).

3 Para un repaso de la historia de la ciencia ficción en España, véase Hesles Sánchez (2013: 23-37), y especialmente el monográfico editado por López-Pellisa (2018a)

4 Reproduzco, por su interés a este respecto, la cita completa de Martín Rodríguez (2018: 108):

Los intelectuales nacionalistas conservadores, encabezados por Ramón Menéndez Pidal y contando con los oficios de alguien tan bien colocado editorialmente como Federico Carlos Sainz de Robles, propagaron e impusieron en su campo, gracias a su prestigio, la idea reductora de que la literatura española siempre había sido sanamente realista, lo que no contribuyó precisamente a que se reconocieran las aportaciones fantásticas y especulativas españolas que sí habían contado con reconocimiento crítico con anterioridad, al menos en la prensa cultural. Entre unos y otros, la ciencia ficción española continuó desarrollándose sin soluciones de continuidad, pero prácticamente fuera de los circuitos de legitimación cultural y política.

5 En efecto, el monográfico editado por López-Pellisa (2018a) ha permitido sacar a relucir un más que significativo inventario de obras poco o nada conocidas hasta fechas recientes, donde reviste especial interés el artículo de Molina Porras (2018) acerca de la producción narrativa anterior al siglo XX. Todo ello no hace sino entrever que, contrariamente a la opinión generalizada hasta hace poco, la ciencia ficción en España no solo existe desde hace mucho - y con una muy buena salud a finales del XIX y comienzos del XX, hasta el parón de la Guerra Civil documentado por Moreno y Pérez (2017: 216)—, sino que entre sus títulos es posible encontrar firmas más que conocidas en los manuales de literatura, como Baroja, Unamuno, Blasco Ibáñez, Pérez de Ayala, Pedro Salinas, Buero Vallejo o Torrente Ballester (Martín y Moreno 2017), por citar tan solo algunos ejemplos.

6 Así, tal y como señala Moreno Serrano (2007: 125), "la literatura española de ciencia ficción ha carecido de interés en el ámbito académico; quizás porque hablar de ciencia ficción implica para la mayor parte del público hablar sobre extravagantes historias de aventuras ambientadas en exóticos mundos”. De igual modo, Moreno y Pérez (2017: 218) indican que " the Spanish academic tradition has always ignored this genre". 
ficción, ${ }^{7}$ cada vez se muestra más receptivo, especialmente en las últimas décadas, cuando es constatable "un cambio de apreciación tanto del fenómeno literario como del propio género [...], dando buenos resultados hasta ahora al elevar la calidad lingüística de las obras y favorecer una mayor exigencia de los autores" (Moreno Serrano 2007: 136). No obstante, cierto es reconocer que, al mismo tiempo, las grandes editoriales aún tienden a mostrar cautela y conservadurismo a la hora de realizar un gran lanzamiento de una obra española categorizable como "ciencia ficción" (Hesles Sánchez 2013: 32 y 58$) .8$

\subsection{La importancia del tiempo}

Tal y como ha apuntado García (2014: 75), “en la ciencia ficción, el tiempo [...] se convierte en la columna vertebral del argumento y también se plantea [...] como una amenaza para el hombre al tiempo que puede ser un material dramático para hablar del presente". En efecto, el tiempo, y los viajes a través de este, suponen la incorporación a la literatura de una nueva estrategia discursiva con la que replantear la naturaleza huidiza y contradictoria del ser humano (Sánchez Usanos 2009: 167). Sea como fuere, lo cierto es que la noción de tiempo, desde el desarrollo de la teoría einsteniana, se ha teñido de relativismo, a la vez que se ha visto vinculado a las condiciones específicas del observador y a la dimensión espacial de los distintos fenómenos (Udías Vallina 2014: 25-26). De este modo, el valor subjetivo del tiempo comporta un proceso relacional: "una conciencia absolutamente sola y vacía es una conciencia atemporal que no puede distinguir un momento de otro ni, consecuentemente,

\footnotetext{
7 Véase, tan solo como muestra, la excepcional labor de recopilación bibliográfica llevada a cabo por Martín Rodríguez (2016a, 2016b y 2017a).

8 Así, Rosa Montero, en una entrevista (Martín Rodríguez 2017b: 63-64), reconoce, por ejemplo, que su obra Temblor se vendió como fantasía en vez de como ciencia ficción, o que Lagrimas en la lluvia o El peso del corazón — sobre las que hablaremos más adelante- se han vendido menos que la media de sus libros, fruto en parte de un menor interés editorial por promocionar esta clase de textos: “algunos escritores niegan escribir ciencia ficción, pese a hacerlo, porque deben de estar hartos de que los ninguneen por ello” (Martín Rodríguez 2017b: 69).
} 
desplegar su vida y su temporalidad" (Garrido-Maturano 2014: 41). Así, solo la relación con lo/el Otro posibilita el desarrollo de las ideas de pasado, presente y futuro, al igual que la presencia del reloj, del instrumento de medición, supone la presencia del tiempo per se, desvinculado de acciones, procesos o acontecimientos: "el tiempo de las sociedades con reloj es lineal y espacial, está descontextualizado y cuantificado, es una continua oscilación representada por un número, es repetición de lo mismo" (Grande 2014: 60). El tiempo, y su transcurrir, en suma, surgen en cuanto fruto de una mera percepción interna "que no se apoya en ningún órgano sensorial y que es imprescindible para realizar operaciones en el espacio [...] y para poder planificar acciones a futuro" (García-Borreguero 2014: 67). Solo nuestra impresión de que algo ha cambiado determina, en resumen, la existencia del tiempo, lo que hace que este se convierta en una cuarta dimensión en igualdad de condiciones con las variables que otorgan volumen a un objeto. Desde esta perspectiva, la supervivencia temporal sería consecuencia tan solo de la identidad entre diferentes partes temporales de un mismo género de objeto (Bordes Solanas 1998: 62-70). No obstante, esta discontinuidad temporal haría que careciésemos "de soporte ontológico para atribuir responsabilidad moral a un individuo con base a sus acciones pasadas" (Bordes Solanas 1998: 72), con lo cual parece no quedarnos otra solución que afirmar que "existe una esencia real individual común a cada persona ( $\mathrm{y}$ a sus contrapartidas posibles) como base metafísica de su supervivencia" (Bordes Solanas 1998: 73).

Lo cierto es que a nadie se le escapa la constante preocupación de la literatura por el tema del tiempo e, indirectamente, por los desplazamientos a través de este, dando lugar así, en cierto modo, a una rama de la literatura de viajes (Sánchez Usanos 2009: 155). ${ }^{9}$ Sin embargo, irónicamente, en la ciencia ficción española, la presencia

\footnotetext{
9 Para un repaso de algunos de los principales relatos sobre viajes en el tiempo, desde el siglo XVIII hasta finales del siglo XX, véase Arranz (2014).
} 
de este tema es absolutamente residual, ${ }^{10}$ salvo excepciones, hasta épocas muy recientes (Hesles Sánchez 2013: 741), lo que no hace sino acentuar el interés por aquellas propuestas narrativas que han apostado - tal y como tendremos ocasión de comprobar en alguna de las obras que analizaremos- por proporcionar una impronta en castellano a un tema de notable desarrollo en otras tradiciones, fundamentalmente, la anglosajona.

\subsection{Virtualidades y universos paralelos}

En la historia de la ciencia ficción, no han sido pocos los casos en los que se ha jugado con la idea de modificar la memoria de un personaje para producir una realidad diferente o alternativa. En este tipo de ciencia ficción, "la virtualidad del nuevo mundo depende únicamente del recuerdo de un mundo real anterior [...] el olvido de la existencia del mundo real implicaría la aceptación de la realidad del mundo virtual" (Muñoz Corcuera 2009: 2). Este mundo virtual supondría una "experiencia de inmersión total" (Muñoz Corcuera 2009: 2-3) que llevaría a los personajes, en última instancia, a ser incapaces de "distinguir entre mundo real y mundo virtual debido a la enorme calidad técnica de las reproducciones virtuales" (Muñoz Corcuera 2009: 3). ${ }^{11}$

Lo cierto es que uno de los aspectos más interesantes del mundo virtual es el hecho de que, en este, las experiencias "pasan a la memoria del sujeto exactamente del mismo modo que las experiencias vividas en el mundo real" (Muñoz Corcuera 2009: 5), llegando incluso a una situación de indiferenciación de olvidarse el paso de un mundo a otro, lo que llevará a una equivalencia ontológica y

\footnotetext{
10 Otro tanto ocurre con la labor investigadora llevada a cabo al respecto: "en ningún caso se ha desarrollado un trabajo académico sobre el viaje en el tiempo en la literatura de ciencia ficción española” (Hesles Sánchez 2013: 38).

11 Tal y como lo plantea López-Pellisa (2015: 20), “el espacio virtual es aquel generado por la actividad cerebral del ser humano. Es el espacio entre el que transitamos cuando imaginamos, cuando soñamos, cuando nos relacionamos con el más allá”. De este modo, la realidad virtual se basaría en "la capacidad de crear la ilusión de simular el espacio real [...] es el modo de mostrarle a un ser humano la ilusión de que se encuentra en otra realidad" (López-Pellisa 2015: 20).
} 
gnoseológica entre ambos universos. Esto se hará especialmente notable en el caso del ciberespacio, entendido este como "el espacio intangible mediado por entornos virtuales donde el ser humano construye su vida de manera paralela con el entorno físico o real" (Hermann Acosta 2012: 108). De este modo, los personajes, en este tipo de narrativa, habitarán un nuevo espacio, donde la "colonización” escapa a la mera existencia real. En todo este ámbito de nuevos universos, o mundos virtuales, la memoria juega un papel crucial, no solo por su naturaleza deformadora, respecto al pasado evocado (Muñoz Corcuera 2009: 6), sino por su capacidad para incorporar al recuerdo sueños y experiencias inventadas o no vividas como si hubiesen sido reales (Muñoz Corcuera 2009: 7-8), fenómeno tremendamente fértil entre los novelistas y dramaturgos modernos, al crear mundos compuestos "totalmente con las realidades psíquicas de los protagonistas” (Bruner 1986: 26).

En estrecha conexión con la realidad virtual, o psíquica, asistimos al desarrollo de los denominados "mundos paralelos", los cuales parten de la teoría de la múltiple ocupación o tesis de la coincidencia, que plantea que dos o más objetos pueden coincidir en el mismo espacio al mismo tiempo, o que existen vidas paralelas ocultas (Bordes Solana 1998: 70). ${ }^{12}$ Steimberg (2016: 29) explicará la diferencia entre mundos posibles y universos ficcionales en los siguientes términos:

Los mundos ficcionales [...], a diferencia de los mundos posibles, se fundan en la noción de paralelismo y no en la de ramificación: mientras los mundos posibles se basan en una lógica de ramificación que determina el arco de posibilidades emergente de una situación real y concreta, los mundos ficcionales se basan en una lógica de paralelismo que garantiza su autonomía respecto al mundo real [...]. El mundo ficcional [...] se construye como un mundo con

\footnotetext{
12 La idea, basada en la noción de "multiverso", o conjunto de muchos universos, tiene entre sus pilares la noción de que "dentro de estas realidades alternativas se encuentran las que surgen como una modificación en la línea temporal [...] Estos viajes pueden crear mundos alternativos [...] que chocan directamente con la experiencia vital que había tenido el crononauta" (Escandell 2016: 236).
} 
una posición ontológica distintiva, un sistema autosuficiente de estructuras y de relaciones; los mundos posibles, en cambio, no comparten esa autonomía ontológica [...] los hechos ficcionales no se relacionan con lo que podría haber ocurrido o con lo que podría no haber ocurrido en la realidad, sino con lo que ocurrió o pudo ocurrir en la ficción.

\subsection{Ontología e identidad}

En la ciencia ficción, los problemas identitarios y ontológicos afloran en no pocas ocasiones, bien como consecuencia de lo que Cuadros Contreras (2008: 261) denomina la "construcción subjetiva del yo", a partir de la naturaleza intrínsecamente artificial del hombre, bien en cuanto fruto del desarrollo de los llamados relatos de duda ontológica, donde se produce un conflicto entre lo concreto y lo virtual, y que desencadena la angustia de los personajes ante acontecimientos que alteran su percepción de lo que es real. Esta duda ontológica sería consecuencia de la irrupción de diferentes mundos posibles o universos paralelos, con lo que la otredad que genera el discurso de la ciencia ficción permitirá al individuo habitar distintos mundos o espacios, lo que lo llevará a dudar acerca del universo en el que se encuentra. De este modo, en la ciencia ficción ontológica ${ }^{13}$ ocurre "algo que perturba las certidumbres de los personajes sobre el mundo en el que están, pero esto sucede en virtud del universo construido, en el que la existencia de diversos niveles de realidad es una posibilidad" (Steimberg 2016: 141).

13 La ciencia ficción ontológica, amparada en la existencia de una duda, es definida por Steimberg (2016: 37) a partir de un conflicto entre lo concreto y lo virtual, entre lo verdadero y lo ilusorio, lo que supone una exploración de "la angustia ontológica de los personajes frente a eventos que perturban su percepción de lo real”. De este modo, en este tipo de historias, el sujeto no está seguro de dónde se encuentra, ni de qué es, fruto de un "problema cartográfico" que emana del hecho de que el personaje "puede habitar distintos espacios o mundos”, pero "no puede saber dónde se encuentra” (Steimberg 2016: 138-139). Y así, estas historias, localizables en parte de la narrativa de autores como Philip K. Dick (Steimberg 2016), por ejemplo, suponen el desarrollo de diferentes sistemas de realidad que ponen en escena "la pérdida de certezas con respecto a la naturaleza del mundo en el que se encuentran” los personajes (Steimberg 2016: 141 y 145-146). 
En conclusión, la ciencia ficción, a partir de sus diferentes propuestas, hace de las reflexiones en torno al tiempo, a la identidad y a la ontología de los espacios físicos y mentales un entramado filosófico con el que construir historias donde estos elementos se interconectan desde una base predominantemente subjetiva y relativista que otorga al personaje la carta de navegación con la que dilucidar los valores absolutos de las situaciones de perplejidad e indefinición a las que se enfrenta.

En consonancia con ello, el objetivo de las próximas páginas será analizar, a partir de dos obras y subgéneros concretos - El mapa del tiempo/Lágrimas en la lluvia y el steampunk/ciberpunk, respectivamente-, cómo se lleva a cabo la formulación de dichos temas desde diferentes perspectivas y soluciones. Para ello, se han seleccionado las dos citadas obras en función de varias concomitancias: no más de una década en el mercado, escasa distancia —apenas un trienio - entre los años de publicación, autores - Félix J. Palma y Rosa Montero- y relatos de éxito (salvando las correspondientes distancias), historias seminales dentro de la trilogía en la que se integran y muestras significativas y más o menos paradigmáticas de los subgéneros - considerados antagónicos con frecuencia, tal y como se verá a continuación- con los que se suelen poner en relación. De igual modo, en ambas obras, y de manera muy marcada, la idea de tiempo, la construcción de realidades paralelas o virtuales y los problemas ontológicos e identitarios salen a relucir una y otra vez, afectando no solo a la propia estructura del relato sino también a los temas, a la configuración de los personajes o al devenir de las historias narradas. ${ }^{14}$

14 En cualquier caso, la selección en modo alguno pretende resultar excluyente, máxime teniendo en cuenta el actual aluvión de novelas cercanas a los mencionados subgéneros, publicadas, entre otros, por Jorge Carrión, Vicente Luis Mora, Laura Fernández, Óscar Gual, Robert Juan-Cantavella, etc. Véase, al respecto, el capítulo de Moreno Serrano (2018) en López-Pellisa (2018a). 


\section{El mapa del tiempo y el steampunk}

\subsection{El steampunk}

Definido por Fernández (2011) como un subgénero que "aboga por un retrofuturismo salvaje que devuelve al mundo a la época victoriana y lo inunda de los avances técnicos (de estética golosa y decididamente artesanal) que aventuran las novelas de Julio Verne", el steampunk parte de la premisa de que "la civilización no tomó el camino de la electrónica y los modernos combustibles sino el de la vieja tecnología del vapor [...] Un mundo avanzado, hecho de la extraña [...] combinación de hierro, carbón y vapor" (Fernández 2011). De este modo, el steampunk desarrolla ucronías con una marcada ideología científica, ${ }^{15}$ que posibilita la presencia más o menos anacrónica —en la Inglaterra decimonónica- de toda clase de inventos y dispositivos, dando a la estética retrofuturista — basada en una visión fantasiosa del pasado histórico, en el cual ciertas tendencias tecnológicas habrían evolucionado de forma mucho más veloz de lo que realmente sucedió- y a la presencia de personajes históricos y literarios un peso específico en el desarrollo de las historias (Matangrano 2016). De este modo, a partir de la nostalgia por un pasado que nunca existió al que se le añaden influencias futuristas y un imaginario con un fuerte componente artístico (Prieto Hames 2016: 96), se crea un género en el cual la partícula “-punk" añade la noción de marginalidad (Matangrano 2016: 247-248) y de actitud crítica ante el actual desarrollo social e individual.

Surgido a finales de los años 80 del pasado siglo con autores como K. W. Jeter, Neal Stephenson, Tim Powers o James P. Blaylock, el steampunk bebe, como fuentes principales, de los relatos futuristas de H. G. Wells y Julio Verne. En al ámbito español, junto con la obra que nos va a ocupar, son de reseñar textos como

15 A pesar de ser considerado un subgénero de la ciencia ficción, no son pocos quienes han insistido en apuntar problemas de clasificación genérica, pues no es raro encontrar en este tipo de obras rasgos cercanos al universo mágico de la fantasy, lo cual lleva "a la disolución de categorías o fronteras a la que tiende un género como el steampunk" (Conte Imbert 2011: 264). 
Lendaria (2013), de Josué Ramos; Danza de Tinieblas (2005), de Eduardo Vaquerizo; La máquina del juicio final (2013), de Raúl Montesdeoca, o El dirigible (2013), de Joseph Remesar, por citar tan solo algunos ejemplos.

Uno de los aspectos más fecundos en el ámbito de la narrativa steampunk es, sin duda, el desarrollo de propuestas ucrónicas donde se crea una hipótesis plausible a partir de algo que hace derivar el curso de la historia (Matangrano 2016: 250). Así, en el caso del steampunk, ese algo es, con frecuencia, el desarrollo de un mundo movido a vapor. De una u otra manera, ese condicional contrafáctico “¿y si...?” parece definir en gran medida al género, volcando la mirada hacia un pasado reformulado en base a un futuro que nunca llegó a ocurrir: "the idea is to re-elaborate situations that existed in the past by asking what would have happened if certain technical interventions had taken different directions" (Pegoraro 2013: 1853). Así, ese cambio de destinos, e incluso de la propia historia, se nos muestran en un universo alternativo teñido con frecuencia de las aspiraciones y temores del individuo decimonónico. De este modo, “el efecto especulativo de la ucronía depende de la existencia de un paralelismo virtual entre ambos transcursos históricos $[\ldots]$ siempre existe una relación dialéctica implícita o expresa con el presente" (Martín Rodríguez 2013: 70).

2.2. El mapa del tiempo. Viajes por la cuarta dimensión y universos paralelos

El mapa del tiempo ${ }^{16}$ conforma un relato ambientado en el Londres de 1896, cuyo punto nuclear es la imbricación entre sus tres personajes principales -Andrew Harrington, Tom Blunt y el célebre escritor H. G. Wells- y la concatenación de viajes en el tiempo fingidos, fantásticos o reales - de los protagonistas. De este modo,

16 La obra — publicada por primera vez en el año 2008, por Algaida Ediciones- es el primer y más exitoso —-merecedor del XL Premio Ateneo de Sevilla— volumen de la denominada "trilogía victoriana", conformada por el citado título, junto con El mapa del cielo (2012) y El mapa del caos (2014). 
mientras Andrew, engañado por su primo Charles y por el propio Wells, cree viajar al pasado, gracias a un extravagante dispositivo, para evitar el asesinato de la prostituta a la que ama a manos del mismísimo Jack el Destripador, Tom - mero actor de una pantomima urdida por el empresario Gilliam Murray para convencer a los londinenses de que pueden viajar al futuro gracias a una suerte de agencia de viajes - convencerá - fruto de sus intereses puramente carnales - a la ingenua Claire de que ha regresado desde el futuro para entregarse a ella. Por último, Wells, a diferencia de los anteriores, sí que viajará, por una sucesión de azares, al futuro, enfrentándose al dilema de aceptar o no la posibilidad de cambiar su destino.

De este modo, a través de una trama no poco compleja, Félix J. Palma ofrece al lector un texto donde los viajes en el tiempo arrancan de la consideración de este en cuanto dimensión equiparable a las que sustentan el volumen de los cuerpos - "un objeto tiene tres dimensiones [...] pero para que este objeto acabe de tener existencia [...] ha de tener una cosa más: duración [...] Si [...] el tiempo es una dimensión más, ¿qué nos impediría recorrerla?” (98-99)—, ${ }^{17}$ lo que convierte al devenir en una sustancia tan flexible y maleable como ciertos objetos físicos: "necesito que consideren la flexibilidad del tiempo, su capacidad para estirarse o encogerse como un acordeón” (76).

Lo cierto es que, en lo que atañe a los personajes, las actitudes de estos ante los viajes en el tiempo resultan ambivalentes. Así, frente a quienes muestran un más que explícito anhelo por poder desplazarse a lo largo del hilo cronológico — ¿'Saben qué es lo que hace tan atractivos los viajes a través del tiempo? Que todos tenemos deseos de realizarlos. Viajar en el tiempo es uno de los sueños del hombre” (117-118); “todos sus intentos por concienciar a la población palidecieron ante la excitación social que desató la

\footnotetext{
Ante la profusión de citas, y para facilitar la lectura, optamos por reproducir tan solo la página correspondiente, remitiendo a la obra de Palma (2009), en la bibliografía final, para la consulta completa de los datos correspondientes.
} 
idea del viaje en el tiempo" (216)—, encontramos a todos aquellos que, de una u otra manera, manifiestan reticencias, cautela o temor: "no todos piensan que los viajes en el tiempo son beneficiosos para nuestra sociedad, como pueden ver" (111); "no sentía ya curiosidad por ver los lúgubres cuadros que pudiesen aguardarlo más adelante en el futuro, tampoco por retroceder al pasado" (214). No obstante, de cualquiera de las maneras, el relato plantea, una vez asentada la posibilidad de viajar en el tiempo, el desafío ontológico que supone la idea — al margen de que esta sea o no verificable- de considerar la existencia de diferentes mundos posibles, bifurcaciones al fin y al cabo de un universo ante el cual se abre el abismo de la hipótesis y el desafío frente a la inexorabilidad de los hechos: "habría un universo donde a Shackleton le hubiese dado tiempo de acabar con Marcus, y en el que él no viajaría en el tiempo y podría seguir siendo Bertie, pero por desgracia se encontraba en otro universo" (645); “ese simple acto volverá a crear otra bifurcación en esta línea temporal, ya que Frost no les asesinará” (603), etc. Como consecuencia de ello, los personajes se enfrentarán a no pocas paradojas temporales: "me he enamorado de ti en un tiempo que todavía no ha sucedido" (385); “me amarás porque ya me amas” (401), etc.

Uno de los principales problemas que plantea el desarrollo, o la formulación, de los mundos posibles, o paralelos, como consecuencia de los viajes - reales o fingidos - de los protagonistas, es el desdoblamiento, o la duplicidad ontológica, de los personajes, presentes de forma simultánea en diferentes evoluciones de la historia: "esta noche había dos Andrews en el mundo. Se preguntó si su otro yo también lo estaría sintiendo a él” (239), “mi yo futuro te da las gracias, Claire. Y el yo que escribe estas líneas [...] no puede sino devolverte la confianza” (440) o "debería resolver el engorroso problema de que Garrett se viese a sí mismo formando parte de la segunda expedición” (553).

Si analizamos el uso del tiempo como categoría en la obra, y lo vemos desde la clásica compartimentación "pasado-presentefuturo", podemos comprobar cómo se produce en el texto, en lo que al primero de los ámbitos respecta, una confusión entre hechos 
y recuerdos —"lo recordaba todo de una manera extraordinariamente vívida $[\ldots]$ aquellos recuerdos incluso se le antojaban más hermosos que los hechos auténticos" (30)— que supone en última instancia una identidad entre pasado y presente: "el paso del tiempo [...] convertía el borboteo del presente en aquel cuadro terminado e inalterable llamado pasado" (p. 30). Esta suerte de ontología difusa, fruto del viaje al pasado - "el pasado puede hollarse de nuevo" (11)—, no hará sino cuestionar una flecha del tiempo que se resquebrajará más y más a medida que avance el relato.

En segundo lugar, en lo que concierne al presente, la obra muestra una manifiesta actitud, por parte de los personajes, de pesimismo y aburrimiento ante la contemporaneidad, en consonancia con la mirada desacralizadora y crítica ante unas circunstancias históricas frente a las que se muestran refractarios - "el mundo que le había tocado en suerte no la seducía demasiado, ni lo haría nunca" (270); "Claire se preguntó cómo iba a soportar tener que vivir de nuevo, y ya para siempre, en su insulsa época" (340)—, lo que en modo alguno entra en conflicto con la revalorización del presente en cuanto único universo ontológicamente constatable y, por ende, real: "disponían de tres horas para estar juntos antes de separarse para siempre. Tres horas nada más" (384) o "tu nueva vida empieza esta noche, amigo. Aprovéchala bien” (489).

Por último, el futuro se revela en la obra igualmente ambivalente. Así, mientras que por un lado existe una manifiesta actitud optimista — "todos querían viajar al [...] año 2000 [...] un siglo era tiempo más que suficiente para que se inventara todo lo que quedara por inventar y el mundo se transformara en un lugar [...] mágico" (100)—, amparada en el anhelo de conocer el porvenir —” ¿no sentía curiosidad? Yo a veces me pregunto cómo será el mundo dentro de cien años" (191)—, por otra parte no son escasas las descripciones distópicas de los tiempos venideros: "viajó con él al futuro, a aquel Londres devastado entre cuyas ruinas los humanos se escondían como ratas" (143) o "preguntándose si estaba preparada para la vida en el mundo del futuro. Aquella tierra desolada" (316). De este modo, y a pesar de cierta identidad que emana del relato entre 
pasado y futuro - "lo que aún no ha ocurrido para ti, ya ha pasado para mí" (401)—, lo cierto es que los tiempos venideros adquieren valor en la novela en la medida en que contribuyen a apreciar el presente: "vamos a ver Londres reducida a escombros [...] estoy seguro de que una visión tan terrible nos hará apreciar mucho más esta ruidosa ciudad" (284). Pero el futuro, por encima de todo, representa la capacidad de sugerencia, de fabulación —"el secreto del viaje en el tiempo siempre ha estado en nuestras cabezas" (578) —, fruto del innato poder creador del ser humano: "le atormentaba la posibilidad de [...] que en su lecho de muerte [...] surgiese del fondo de su mente [...] el argumento de una novela extraordinaria que ya no tendría tiempo de escribir" (520).

Y así, poco a poco, El mapa del tiempo va gestando una actitud frente al tiempo teñida de un hondo perspectivismo - "al filmarse sesenta y cinco años después, parte de lo que para ti era futuro ya es pasado para el mundo" (632)—, donde las dudas — ¿'y si su vida estaba siendo escrita por alguien de otra realidad, por ejemplo de ese universo paralelo tan parecido al suyo pero donde no existía ninguna empresa de viajes temporales [...]?” (666)—; acaban por conducir hacia una concepción del tiempo en cuanto abstracción puramente ilusoria, tal y como ilustra la cita de Albert Einstein que encabeza el relato: "la distinción entre pasado, presente y futuro es una ilusión, pero se trata de una ilusión muy persistente” (9). En la novela de Palma, pasado y futuro aparecen subordinados a la noción de presente, el cual, a su vez, ofrece una naturaleza evanescente teñida de relativismo, todo ello en consonancia, en gran medida, con la noción de tiempo localizable, por ejemplo, en el estoicismo clásico. Para los estoicos, el presente supone la unión de pasado y futuro, a través de un ahora que se ve disuelto entre lo pretérito y lo venidero, dando así lugar a una entidad abstracta y delimitadora que permanece ajena a la noción cronológica del tiempo y que cobra existencia tan solo mediante la experiencia individual (Dopazo Gallego 2013: 185, 191 y 193). En El mapa del tiempo, como en el estoicismo, todo encamina hacia un presente que da sentido al pasado y al futuro y que ahorma la única realidad 
experimentada por el sujeto, a partir de la constatación de que lo ya concluido y aquello por venir, en términos absolutos, no existen, en la medida en que no dependen de nosotros y escapan al control (Zăhan 2011: 33-34; Dopazo Gallego 2013: 185). Así, una vez anuladas las divisiones temporales, el sujeto se enfrenta a la paradoja de asumir la existencia de un presente ilusorio que es, sin embargo, nuestra única referencia (Dopazo Gallego 2013: 184-186). Por todo ello, mientras que el estoicismo acaba por asumir la irrealidad del tiempo (Dopazo Gallego 2013: 191-192 y 202; Salles 2002: 17-18), la novela de Palma parece encaminar hacia una suerte de anulación ontológica de este — "en aquel mundo sombrío los relojes dejaban de funcionar ${ }^{18}[\ldots]$ no había ninguna señal que delatara el paso del tiempo" (140)_, la cual en ocasiones acaba por verse confundida con el ensueño o con algún estado más o menos alterado de la conciencia: "el hombre estaba atrapado en el devenir del tiempo, por el que solo podía desplazarse de un modo mental" (209) o "Wells se encontró en el miserable callejón trasero [...] con la sensación de que su viaje al año 2000 había sido un sueño" (554).

En conclusión, El mapa del tiempo enfrenta al lector a la eterna lucha entre predestinación/determinismo — "había vivido todo ese tiempo con la certeza de que tarde o temprano volvería a hacerlo" (21) - y libertad: "creo firmemente que nuestro destino no está escrito: Somos nosotros quienes lo escribimos día a día” (285-286) o "podía decirle que el futuro no estaba escrito en piedra, que podía elegir” (391). Precisamente, la existencia de esos posibles mundos paralelos, ${ }^{19}$ ante los cuales el ser humano puede

18 Esta inutilidad de los objetos destinados al cómputo del tiempo no hace sino incidir en la ya clásica diferenciación, de origen platónico, entre el tiempo limitado, contable y cósmico, y el tiempo ilimitado y extra-cósmico, en correspondencia con la distinción entre cronos (tiempo secuencial) y kairós — que representa el momento supremo, imponderable-, respectivamente (Zăhan 2011: 30 y 35).

19 Si bien es este un tema que precisaría de un más amplio debate, y que desborda los objetivos de este artículo, cabe preguntarse, a modo de sugerencia, por la hipotética analogía entre las concepciones cíclicas del tiempo — sustentadas sobre la noción de que el mismo mundo se repite, de una u otra manera, en tiempos o períodos distintos- (Salles 2002), en diferentes representaciones filosóficas, y los universos paralelos, tal y como son tratados por la ciencia y la fantasía especulativa. 
escoger, marca irónicamente un punto de insatisfacción —”podía revelar una envidia en el fondo absurda hacia su gemelo temporal [...] debía contemplar su dicha con la misma satisfacción con la que recibiría la suya propia" (255)—, haciendo que el viaje en el tiempo genere cierta alteridad ontológica — "temiendo ser el blanco de una nueva xenofobia, los viajeros comenzaron a huir a través del tiempo" (582)—, lo que llevará a una suerte de modificación (cuasi) biológica - "el homo temporis, como se les denominó, debía estar vigilado" (580)—, frente a la cual el tiempo, y sus bifurcaciones, se ofrecerán como carreteras, o mapas alternativos, que permitirán al viajero moverse por universos más o menos alejados de un teórico prototipo primigenio: "la cuerda blanca [...] representa el universo original, el único que existía antes de que los viajeros comenzaran a trastocar el pasado" (591). De este modo, El mapa del tiempo incide en la capacidad del individuo para tomar unas u otras decisiones, lo que desencadena en última instancia diversas ontologías paralelas, donde lo real y lo potencial/irreal/posible se entrecruzan, usando el viaje en el tiempo como mecanismo narrativo con el que reflexionar no solo acerca de la naturaleza cuestionable de la propia realidad, sujeta a relativismos, sino en torno a nuestra propia identidad, y la solidez de la autoconsciencia, resquebrajables desde el momento en el que nuestro yo pasado, presente y futuro constituye distintas entidades ante las cuales cualquier toma de decisión, por banal que sea, sirve para modelar, una y otra vez, nuestra esencia más íntima, a partir de ontologías paralelas que, de forma ininterrumpida, seleccionamos sin parar a lo largo de nuestra vida.

\section{Lágrimas en la lluvia y el ciberpunk}

\subsection{El ciberpunk}

El ciberpunk surge en gran medida como consecuencia "del pensamiento de que la unión hombre-máquina se palpa como una realidad muy próxima” (Portero y Linares 2013: 375-376). En efecto, este subgénero, surgido en Estados Unidos a lo largo de 
los años 80 del pasado siglo — con autores tan reseñables como William Gibson, Rudy Rucker, John Shirley o Neal Stephenson-, plantea una práctica de vida basada en la interacción entre hombre y tecnología a partir del desarrollo de la inteligencia artificial y del ciberespacio -ámbito este donde el sujeto se construye y el conocimiento llega a través de la tecnología - en cuanto nuevo ámbito para las relaciones sociales, buscando la interconexión entre género policial, ciencia ficción y novela negra a partir del valor protagónico de la figura del hacker (Hermann Acosta 2012: 110-111). ${ }^{20}$ Por otro lado, es igualmente notable en el género el peso del componente político y económico, en la medida en que el sujeto aparece con frecuencia "sometido a grandes corporaciones mundiales que ejercen un dominio absoluto", con lo cual en el relato ciberpunk "el orden mundial que se plantea es el del capitalismo tardío, liderado por grandes corporaciones globales y saturado por la tecnología y sus desechos" (Areco 2011: 164). ${ }^{21}$ En este ámbito, el protagonista, sujeto marginado, intenta enfrentarse a ese poder omnímodo de alguna manera, dejando así la historia entrever, por lo general, una visión pesimista del mundo. El ciberpunk, en última instancia, acabará desembocando en un postciberpunk menos maniqueo y más relativista, donde predominará la mirada posthumana, caracterizada, en palabras de Steimberg (2016: 130), por cuatro rasgos: el privilegio de la información sobre su mera representación física, la consideración de la conciencia en cuanto epifenómeno, la visión del cuerpo como una mera prótesis manipulable y la articulación del ser humano con las máquinas inteligentes.

En efecto, la disolución entre lo natural y lo artificial, rasgo este característico del ciberpunk, lleva a la irrupción de un personaje nuevo, el cíborg, ser humano cuyo aspecto cambia con frecuencia como consecuencia del uso de todo tipo de prótesis, el cual convive con robots, droides y supercomputadoras en una suerte de

\footnotetext{
20 Véase también López-Pellisa (2015: 58-60) en relación con los orígenes y definición del género.

21 "Refleja un mundo presente en el que la tecnología ostenta la hegemonía de los poderes divinos y del Estado” (López-Pellisa 2015: 60).
} 
contínuum naturaleza-máquina (Cuadros Contreras 2008: 253 y 260). El cíborg, ${ }^{22}$ en efecto, es "un ser formado por materia viva y partes electrónicas, aunque para que los dispositivos electrónicos se integren con los humanos deben trabajar sin conciencia y deben cumplir funciones de forma absolutamente fiable" (Portero y Linares 2013: 383). De este modo, información, tecnociencia y tecnologías de la comunicación se integran para dar a luz a nuevas formas parabiológicas que resquebrajan los límites entre lo natural y lo artificial y "que subvierten el contexto androcentrista” (Portero y Linares 2013: 384). Al mismo tiempo, el robot humanoide, o droide, disuelve de igual modo la distancia entre lo humano y lo técnico, creando una "confusión ontológica”, sobre todo en la medida en que estos robots presentan con frecuencia rasgos de subjetividad (Cuadros Contreras 2008: 248-249).

En resumen, por encima del ciberpunk aletea, a través de su nueva constelación de personajes, el imaginario del monstruo, ${ }^{23}$ el

22 Dada su relevancia dentro de Lágrimas en la lluvia, conviene señalar que la figura del cíborg femenino, dentro de la ciencia ficción, ha consistido con frecuencia en un organismo diseñado fundamentalmente para satisfacer — de forma consentida o nola demanda sexual de los hombres — con excepciones, como la propia obra de Rosa Montero-, de ahí que destacase por su perfección anatómica. Desde este horizonte, las cíborgs que se nieguen a satisfacer los deseos masculinos serán vistas como una auténtica amenaza (Merás 2014), tal y como, en cierto modo, sucederá con la Bruna Husky de Montero. En una línea parecida, López-Pellisa (2017: 313-314) apunta que las mujeres artificiales, en cuanto construcciones culturales dobles, soportan la subordinación patriarcal dos veces — en cuanto hembra y en cuanto máquina-, siendo con frecuencia meros objetos sexuales que encarnan la docilidad - "The imaginary techno-female produced by men in science fiction, then, repeats the same stereotyped, binary gender roles, using the artifacts as replacements for real women"-, una sumisión que por lo general solo se ve rota cuando la autora del relato es una mujer (López-Pellisa 2017: 315), tal y como sucede con Bruna Husky y Rosa Montero. Entre los estudios al respecto de los personajes artificiales femeninos, véase López-Pellisa (2015: 192-199), Pedraza (1998), Mesa Gancedo (2002), Prado Feliu (1998), Broncano y Hérnandez de la Fuente (2010) o Amartin-Serin (1996).

23 Véanse al respecto estudios como el de Foucault (2000) o del Río Parra (2003). Así, mientras que para el primero el monstruo supone la "violación de las leyes de la sociedad", así como de "las leyes de la naturaleza”, en la medida en que se trata del "punto de derrumbe de la ley y, al mismo tiempo, la excepción que sólo se encuentra, precisamente, en ambos extremos. Digamos que el monstruo es lo que combina lo imposible y lo prohibido" (Foucault 2000: 61), para la segunda "no es parte del alfabeto 
cual simboliza en última instancia lo extraordinario, lo anormal, lo diferente, percibido de algún modo como una amenaza; alguien, o algo, que se resiste a ser integrado, y que rompe los esquemas y el orden social de la comunidad (Tur Planells 2004-2006: 699-700). De este modo, el monstruo se erige como una amenaza frente a la identidad, por su naturaleza difusa: "la deformidad, la imagen que no responde a la idea de normalidad, o a la forma reconocida, recibe el rechazo social porque supone una deformidad del espíritu” (Tur Planells 2004-2006: 702). Por todo ello, el monstruo "se encuentra en la encrucijada de lo biopolítico y lo tecnológico”, creando un "intercambio social simbólico entre un subalterno y un Otro dominador”, ${ }^{24}$ lo que no hace sino "perturbar la condición necesaria y uniforme de los discursos dominantes, sobre todo las narrativas construidas en torno a la noción de progreso" (Velázquez Castro 2017: 341-342).

\subsection{Lágrimas en la lluvia: identidad, memoria y ansias de vivir}

La novela ${ }^{25}$ de Rosa Montero gira en torno a la investigación llevada a cabo por la detective Bruna Husky al objeto de intentar averiguar qué se esconde detrás de la muerte de distintos replicantes - organismos biológicos con apariencia más o menos humana creados y modificados genéticamente, y a los que se les ha implantado una memoria con recuerdos artificiales, tal y como de hecho ha sucedido con la propia Husky—, respecto a la cual parece tener no poco pro-

natural o lógico, sino de la crisis de ese alfabeto, que carece de referentes, que funciona como signo enigmático, desconocido” (del Río Parra 2003: 17).

24 Resulta fundamental, en este sentido, el manifiesto de Donna Haraway (1991), donde el cíborg es contemplado en cuanto ente híbrido, difuso e inclasificable, el resultado de un mundo post-género, una criatura monstruosa que, analizada desde las teorías poscoloniales y los estudios sobre la subalternidad, es asimilada por la crítica feminista desde el prisma del sujeto sometido, el cual se enfrenta inevitablemente a una dialéctica de lucha donde la imaginería cíborg sirve para construir y destruir máquinas, identidades, categorías y relaciones. Respecto al valor político del cíborg, véase también García Selgas (1999).

25 La obra, publicada por primera vez en el año 2011, ha dado origen a una serie de novelas con idéntica protagonista, donde hemos de incluir El peso del corazón (2015) y Los tiempos del odio (2018). 
tagonismo la presumible manipulación, con recuerdos adulterados, de la memoria de los propios replicantes. La obra, cuyo éxito de ventas y crítica se ha visto contrarrestado por el silencio académico (Pardo-Fernández 2017: 33), incide en un tema de capital importancia en la película Blade Runner (1982), ${ }^{26}$ y de la cual toma una de sus frases más icónicas para el título: la terrible desesperación de quienes saben, al igual que los replicantes tanto del film de Ridley Scott como del relato de Montero, la fecha de su muerte. Esta especie de "mantra" que supone "la perspectiva siempre amenazante de la propia muerte” cobra protagonismo en la novela una y otra vez (Pardo-Fernández 2017: 36), lo que lleva a otro de los temas cruciales en el relato, la memoria, y en concreto la implantación de esta en el sujeto, lo cual no dejará de representar, en clave metafórica, "la configuración discursiva que las sociedades contemporáneas pretenden imponer a los sujetos" (Pardo-Fernández 2017: 38). De este modo, los recuerdos se convertirán en una suerte de herencia genética que los memoristas - escritores de las memorias implantadas a los replicantes - transmitirán a sus "criaturas” (Konstantinova 2017: 188), ${ }^{27}$ pero al mismo tiempo servirán para reconceptualizar

26 A este respecto, y a pesar de ser sobradamente conocido, resulta crucial recordar la evidente condición de hipotexto de Do Androids Dream of Electric Sheep? (1968), de Philip K. Dick, respecto al célebre film de Ridley Scott. De este modo, la película, al igual que el relato del norteamericano o la novela de Montero, "poseen un fondo común que se desarrolla en el impreciso límite entre lo artificial y lo real, un discurso sobre la decadencia de la vida y la sociedad, que aborda diversos problemas éticos sobre los cyborgs" (Uribe Aguilar 2008: 103).

27 La figura del memorista - muy cercana, por su condición de artesano, a la del diseñador genético J. F. Sebastian en Blade Runner - se halla en cierto modo a caballo entre lo que Escandell (2016: 24-32) denomina "titiritero" —una suerte de controlador que logra expresarse a través de avatares o "marionetas" sobre los que ejerce un dominio indirecto o diferido- y el rol del creador de autómatas, mostrando en cualquier caso más afinidad con este segundo: "los creadores de autómatas [...] quieren [...] crear nuevas vidas o inyectar vida a cuerpos inertes para completar la suya propia. Es un proceso de creación más que de simulación que por supuesto evoca la potencialidad divina como fundadora de vida” (Escandell 2016: 97). De igual modo, en aquellos casos en que los memoristas no hagan sino trasladar parte de su pasado autobiográfico a las memas asistimos, en cierto modo, al "concepto poshumano de almacenar nuestros recuerdos a través de un soporte externo para, de alguna forma, conseguir que se perpetúe nuestra existencia” (Escandell 2016: 205). 
la noción de identidad, otro de los conceptos clave en la obra, por donde circulan toda clase de especies y seres — humanos, cíborgs, extraterrestres, mutantes, etc.- - los cuales someten con frecuencia sus cuerpos a operaciones de modificación anatómica y/o cognitiva (Konstantinova 2017: 189-190). Por ello, en suma, la idea de alteridad se manifiesta una y otra vez a lo largo del texto, el cual "critica un conjunto de perspectivas ideológicas que condicionan la otredad como amenaza, problematizando la construcción del sujeto y del otro (o los otros) en la realidad social” (Pardo-Fernández 2017: 31). De este modo, Montero parecería abogar por una existencia poshumana donde las fronteras entre las especies se diluyeran y todos convivieran en situación de igualdad, ${ }^{28}$ aceptándose y colaborando unos con otros: "Montero calls for personal change both in the way we accept ourselves and the way we treat others, be they of a different race or species” (Konstantinova 2017: 191). ${ }^{29}$

Pasando al análisis de la obra, y a uno de sus elementos fundamentales, la identidad, llama la atención, en primer lugar, como ya se ha apuntado, esa suerte de alteridad beligerante que surge entre no pocos de los personajes, ${ }^{30}$ fruto de las ideologías supremacistas humanas, ${ }^{31}$ reforzadas por el sentimiento de amenaza ante

\footnotetext{
28 Recordemos, en este sentido, que del Río Parra (2003: 29-30) apunta, como un cambio de paradigma en torno a la figura del monstruo, el hecho de que este, a partir del siglo XVII, pase de estar en el lejano Oriente a encontrarse en casa, tal y como sucede en la novela que nos ocupa.

29 Si bien escapa a los objetivos de este artículo, no está de más indicar que otras, como Leone (2017), han incidido en la naturaleza feminista y ecocrítica de la obra, al establecer analogías entre la explotación del medioambiente y la opresión a las mujeres, los pobres y los grupos minoritarios, haciendo así que las alianzas que se desarrollan en la novela entre seres de diferentes especies y zonas geográficas sugieran que un paradigma relacional centrado en el cuidado puede proporcionar las bases para la sostenibilidad ecológica, económica, política y social.

30 A este respecto, Sanz (2017:324) comenta que muchas de las relaciones de la obra "are based on prejudices and characterized by hatred and hierarchical thought".

31 Esta tensión, en palabras de Sanz (2017: 328), es uno de los componentes clave del texto: "Tecnohumans have coexisted with humans for some time in the world of the novel, but we can still perceive the tension between them as a kind of speciesism -in fact, this tension is an essential component in the plot".
} 
la irrupción de cíborgs asesinos: ${ }^{32}$ "¿te molesta saber que estamos hartos de aguantaros? ¿Que no vamos a dejar que sigáis abusando de nosotros?" (207) ${ }^{33}$ o "por lo menos los disturbios han hecho que desaparezcan los malditos reps. ${ }^{34}{ }$ No hay ni uno por las calles! Da gusto, ¿no?” (263). ${ }^{35}$ De este modo, la pretendida inserción social del Otro en la obra — fundamentalmente a través de la imagen del replicante como un miembro más de la comunidad- choca de manera frontal con un tejido de especies en el que el humano reclama su superioridad, al tiempo que ve al rep. como un potencial asesino/criminal. Pero irónicamente, la propia Husky, a pesar de sufrir en sus propias carnes la vejación y el insulto, dada su condición de replicante, ${ }^{36}$ mostrará idéntica actitud de menosprecio, ${ }^{37}$ en este caso hacia el extraterrestre con el que acaba de mantener relaciones sexuales: “¿de verdad se había acostado con un bicho? Es

32 En cierto modo, los sentimientos humanos serán muy semejantes a los que podamos encontrar en Blade Runner: "son los humanos quienes padecen esta contradicción: admiran la perfección de los replicantes y, a la vez, los temen y los exterminan” (Vizcarra 2011: 56).

$33 \mathrm{Al}$ igual que con El mapa del tiempo, optamos por indicar tan solo el número de la página correspondiente, remitiendo al lector a la bibliografía final para la consulta de la referencia completa (Montero 2016b).

34 Forma hipocorística de "replicante".

35 "La violencia [...] la voluntad lisa y llana de supresión”, como apunta Foucault (2000: 62), es el principal mecanismo de respuesta ante el monstruo, más que el uso de la propia ley.

36 En efecto, una de las claves de la novela es, sin duda, el hecho de que la protagonista encarne la representación del Otro a partir de su categorización como cíborg, generando en el relato una evidente situación de alteridad, dada su condición de replicante, frente a otras formas biológicas igualmente presentes en la novela (humanos, extraterrestres, etc.): "Bruna herself is such an other: she looks human except for some physical traits that give away her artificial origin" (Sanz 2017: 323-324).

37 Así, al decir de Foucault (2000: 51), el rechazo, en sus múltiples variantes, es la fórmula de reacción ante todo aquello que conceptualizamos como lo/el otro:

Las prácticas de exclusión, prácticas de rechazo, de marginación [son] las formas en que se describe, y creo que aún en la actualidad, la manera en que se ejerce el poder sobre los locos, los enfermos, los criminales, los desviados, los niños, los pobres. En general, se describen los efectos y los mecanismos de poder que se ejercen sobre ellos como mecanismos y efectos de exclusión, descalificación, exilio, rechazo, privación, negación o desconocimiento; es decir, todo el arsenal de conceptos o mecanismos negativos de la exclusión. 
decir, ¿había...? El solo merodeo mental a esa idea impensable hizo que se le aflojaran las piernas" (133)..$^{38}$ Todo ello, en suma, no hace sino evidenciar una conflictividad más que latente entre las distintas especies, y que en modo alguno la convivencia ha logrado disolver. Unos y otros, pues, configuran estrategias de rechazo ante aquello que es percibido como distinto, mostrando así, una vez más, el atávico miedo al monstruo o, de forma más diluida, al anormal.

Sin embargo, y a pesar de las líneas más o menos definidas que marcan las distancias entre las especies ${ }^{39}$ lo cierto es que en ocasiones los personajes se enfrentan a situaciones de confusión identitaria: “¿Estás loca o te lo haces? También eres una replicante... Mírate al espejo... ¡Mírate a los ojos! Eres tan tecnohumana como yo" (14) o "- ¿No quieres saber quién eres? —Sé perfectamente quién soy. -Lo dudo" (360). Esta confusión, a veces, acabará desembocando en un puro dualismo ontológico, a partir de la constitución de dos yoes: "cuando el viejo Yiannis recordaba ahora al Yiannis veinteañero jugando y riendo con su crío, era como si rememorara a algún conocido de la época remota de su juventud, a un amigo" (47). En consonancia con esto, la modificación quirúrgica de la identidad, por uno u otro motivo, será otra constante, a lo largo de la obra: "el líder supremacista era un tipo repugnante de mejillas siliconadas, pelo injertado" (98-99) o "estaba golpeando furiosamente su brazo biónico con un pequeño martillo de goma” (217)..$^{40}$ Todo ello llevará, en suma, a una visión cada vez más difusa de la identidad propia - "en los cuarenta y nueve años transcurridos, todas y cada una de las células de su cuerpo se habían renovado. Ya no quedaba

38 Como indica Sanz (2017: 323), "Bruna Husky interacts with nonhuman creatures both in direct and indirect ways and focuses her attention on creatures that have traditionally been labeled the other".

39 Lo cierto es que las relaciones entre las especies, en Lágrimas en la lluvia, se articulan, más que por la conceptualización del monstruo como tal, a través de lo que Foucault denomina el anormal, esto es, "un monstruo cotidiano, un monstruo trivializado", que rebaja o confisca parte de los rasgos de lo monstruoso (Foucault 2000: 63 y 298).

40 Lo mismo sucede con la película de Ridley Scott: en Blade Runner, tanto los replicantes como los humanos son naturales (nacidos, de algún modo) y artificiales (construidos, social, cultural o tecnológicamente, de una u otra forma...) a un tiempo (Belmonte Arocha y Guillamón Carrasco 2005: 3). 
ni una pizca orgánica original del Yiannis que un día fue” (48)—, proceso este de disgregación frente al cual solo aparece en cuanto elemento cohesionador el amor — "ni con el mejor de los amigos llegarías a ocupar ese lugar básico de pertenencia al otro" (154) o, más concretamente, el sexo, tal y como explica el extraterrestre Maio: "Totalmente cerca. Íntimamente cerca. Todo lo cerca que pueden estar dos seres. Cuando dos seres hacen guraam, se rozan [...] se pueden leer mutuamente el pensamiento. Guraam significa conexión” (301).

Junto con la identidad -y sus problemas-, el tiempo, y en concreto el paso de este, marca otro de los elementos nucleares del relato. En este sentido, el pasado cobra un especial valor, no solo por convertirse en ocasiones en una auténtica obsesión para los personajes —"la pantalla emitía imágenes sucesivas del niño [...] una pareja perfecta y entrañablemente unida por el culto a sus muertos" (405)—, sino por las dudas que en torno a este mantienen los replicantes —a los que, no lo olvidemos, se les ha incorporado una memoria artificial, espuria-, y en particular Bruna. Así, los recuerdos reales — "Cuando su amante murió, Bruna tiró el vidrio: no podía soportar esa imagen de dicha” (232) - convivirán en situación de igualdad con los falsos, implantados con la ayuda de la biotecnología - "a todo androide se le implanta un juego completo de memoria con suficiente apoyo documental real" (25)—, y que determinarán el elemento nuclear de la novela, esto es, la locura de algunos replicantes como consecuencia de la manipulación de sus recuerdos: "nadie explica que hay unas memas adulteradas que están enloqueciendo a los reps.” (119). En este sentido, la manipulación y creación de recuerdos —"se trata de un recuerdo implantado, supuestamente sucedido en torno a los catorce años del sujeto" (26) — no hace sino llevar a la constatación de que el pasado es impostado - "Bruna jamás había tenido veinte años, aunque los recordara” (312) —, y que por tanto puede ser comercializado como cualquier otro producto: "quiero una mema. ¿Tú vendes? [...] son muy caras $[\ldots]$ antes solían venir por aquí un par de vendedores 
de memas [...] las cosas se están poniendo feas en el mercado de memorias" $(80-81){ }^{41}$

Lo cierto es que los recuerdos, en Lágrimas en la lluvia, tienen una irónica ambivalencia que hace que, por un lado, estos sirvan de consuelo - "no se veía ninguno de los pequeños recuerdos artificiales siempre tan comunes [...] pese a conocer su falsedad, los objetos [...] seguían ofreciendo consuelo y compañía" (34)—, pero, a su vez, generen dolor: " $¿ y$ el dolor? ¿Todo ese dolor que tengo dentro? ¿Todo ese sufrimiento en mi memoria?” (93). Aún más dolor, o incluso angustia y desesperación, generará la falta de recuerdos - "en busca de un alivio, de una memoria en la que poder creer, de unos recuerdos que la permitieran descansar durante cierto tiempo" (35)—, llegando al punto de preferir la memoria fidedigna, por terribles que sean las vivencias rescatadas, al artificial y narcotizante recuerdo impostado: "también había individuos que, aunque arrastraban una piedra en el corazón, se negaban a utilizar la máquina [...] como ella misma. Ella quería seguir recordando a Merlín, aunque doliera" (356). Todo esto, en suma, no hará sino desencadenar una actitud relativista ante el pasado - "qué débil, qué mentirosa e infiel era la memoria de los humanos" (48)—y, por tanto, una vacilación ante la entidad ontológica de los recuerdos: "el recuerdo de mi hijo. jera tan real! Y todo ese cariño y ese dolor" de ese nombre [...] y ahora toda la información se sucedía de modo torrencial [...] ¿ sería verdad que se había equivocado?” (389).

De este modo, el relato de Rosa Montero otorga tal protagonismo narrativo y filosófico a la idea del pasado, del recuerdo, que llega a verse identificado directamente con la existencia: "miró la

\footnotetext{
${ }^{41}$ La posibilidad de insertarse memas con efectos más o menos narcotizantes parte de la idea — apuntada por Escandell (2016: 163) — de llevar a cabo una okupación del yo a partir de la "creación de otros entes propios [...] casos particulares de usurpación y engaño no solo hacia los demás, sino hacia uno mismo [...] el engaño no es solo externo, sino también interno, para la propia psique del suplantador".

42 López-Pellisa (2015: 99-100) se referirá a este tipo de confusiones como "metástasis de los simulacros", los cuales constituyen una "metáfora de la propagación, proliferación, penetración e invasión de los simulacros en el tejido de lo real”.
} 
mema y pensó: es como tener un cadáver en mi mano. Aún peor: era como tener a alguien vivo encerrado ahí dentro” (83). Y así, la identidad, la autoconsciencia, surgirá, sobre todo, como consecuencia de los recuerdos — "necesitaba verle, necesitaba preguntarle sobre la madre, sobre el padre, sobre la infancia, quería saber más cosas, más detalles, tenía hambre de más vida” (427)—, ${ }^{43}$ pero, puesto que estos son en gran medida falsos - "te han metido un implante de comportamiento inducido. Te han hecho creer que tienes un hijo" (412)_, se produce un irremediable conflicto entre la memoria y la propia esencia del individuo: "Pero Bruna siguió adelante [...] escarbando una y otra vez en la carne viva, hasta llegar al recuerdo final y reventarlo [...] Bruna Husky estaba de regreso, toda entera” (415416). Y todo ello no hará sino alimentar una confusión entre sueños y recuerdos — "pero quedan restos... pizcas de sentido. Aunque se van borrando rápidamente. Como se borra el recuerdo de un sueño a medida que el día avanza" (442) — que emana de una historia en la que la construcción de universos mentales, a partir de recuerdos fidedignos o impostados, permite el desarrollo de la trama y otorga sentido a la vida de los protagonistas: "Nopal [...] era dramaturgo y novelista, además de memorista" (69); "la memoria es la base de nuestra identidad, así que de alguna manera yo soy el padre de cientos de seres. Más que el padre. Soy su pequeño dios particular” (91), etc.

Pasando al presente, Lágrimas en la lluvia muestra de nuevo cierta ambivalencia al respecto. Así, mientras que por un lado el presente adquiere un especial valor para los protagonistas - "pero estaban juntos y aún estaban vivos [...] aquella noche se detuvo el tiempo y hubo una extraña paz en el dolor" (242)—, fruto de las ansias de vivir - "por mucho que vivas, nunca es suficiente" (456)_, algunos de los personajes manifiestan en ocasiones, paradójicamente, un hastío hacia el presente — "por eso consumimos

\footnotetext{
43 A este respecto, y en relación con Blade Runner, Montes Pérez (2004: 302) apunta cómo "es una obsesión por parte de los replicantes la posesión y experiencia de un pasado, de un origen, de algún dato que les sirva de referencia, no sólo para saber quiénes son, sino para entender lo que sienten".
} 
drogas y nos metemos memorias artificiales: queremos escapar del encierro de nuestras vidas" (64) — que desemboca en una clara actitud pesimista ante la vida: "si la gente fuera consciente de lo que cuesta morirse, perdería la fe en la vida” (309-310). De cualquiera de las maneras, y al igual que había sucedido con el pasado, el presente se convertirá en un mecanismo para la constitución de la identidad de los personajes: “yo no soy mi memoria. Que además sé que es falsa. Yo soy mis actos y mis días" (91) o "lo que hago es lo que me enseña lo que estoy buscando" (357).

Por último, en lo tocante al futuro, este constituye, junto con el pasado, uno de los pilares fundamentales en la configuración del relato y de la protagonista. No olvidemos que Bruna, como replicante, sabe perfectamente cuándo se va a morir, y esto desemboca en una suerte de visión determinista que sobrevuela a lo largo de toda la historia - "la temprana fecha de caducidad de los replicantes les impedía reunir los puntos necesarios para acceder a una adopción normal” (29) — y que acaba por identificar la muerte con el tiempo: "su obsesiva cuenta atrás sólo indicaba el tiempo que le quedaba hasta llegar a la fatídica frontera de los diez años; pero, a partir de ahí, el TTT podía tardar dos o tres meses en acabar con ella" (334);4 "la volvía a dejar sola consigo misma, tan a solas con su tiempo limitado y su condena a muerte" (354), etc. Porque, en efecto, la constatación de que la fecha de su muerte está clara y nítida en el calendario martilleará el cerebro de la protagonista hasta en casi una treintena de ocasiones a lo largo de la novela —”cuatro años, tres meses y veintisiete días" (29)—, y encaminará hacia la desoladora unión entre un pasado-recuerdo que no existe y un futuro con incontestable fecha de caducidad: "entre los dos vectores, la suma ascendente de la memoria y la descendente de la propia vida, se abría el gran agujero de los terrores, el insoportable sinsentido" (311). Sin embargo, ese pasado/futuro falso - "todo es

44 La consciencia de la propia muerte, y los conflictos que esto genera, son, de nuevo, elementos que vinculan la novela de Montero con Blade Runner: "su eje central es la mortalidad, el drama de la conciencia del ser que se niega a su propia extinción, que no logra aceptar cabalmente su regreso inevitable a la nada" (Vizcarra 2011: 37). 
mentira... Los afectos... La memoria de esos afectos. El amor de mis padres [...]. Todo se lo tragó la nada. No existe, ni existió” (153)— no impedirá a la protagonista, hacia el final de la obra, exorcizar a sus propios fantasmas, ofreciendo un brillo de esperanza ante el hecho de seguir viva un día más: “-Pues parece que tampoco hoy se acaba el mundo - dijo la rep. - Se diría que no. - Bueno. Es un alivio" (476).

En conclusión, Lágrimas en la lluvia representa, por encima de todo, la duda gnoseológica: “- ¿Cómo... ejem... cómo sabías que Nopal había sido mi memorista? —No lo sabía. — ¿Y cómo sabes que no he matado a Hericio? —No sé si lo has hecho. - Entonces, ¿por qué me ayudas? - Tampoco lo sé” (424). Bruna, en suma, solo puede aceptar el rechazo a la identidad propia ${ }^{45}$ como mecanismo para alcanzar la libertad — "hay algo maravilloso en desprenderse de uno mismo... Esa suprema libertad de dejar de ser quien eres" (474)_, mostrando, a partir de ahí, solo dos elementos consolatorios con los que desafiar al tiempo y a la sinrazón de una vida sin pasado ni futuro, esto es, la belleza — "conoces [...] la emoción de una música hermosa [...] también te he dado la belleza, Bruna. Y la belleza es la única eternidad posible" (464) — y el amor:46 "se apretó contra él hasta conseguir rozarle el corazón y hasta matar a la muerte” (462). De este modo, ante un pasado carente de verificación y un futuro con un final tan certero como descorazonador la replicante solo puede entregarse al amor y a los fugaces momentos de deleite estético, para encontrar en un presente siempre fugaz pero seguro al fin y al cabo el único asidero al que aferrar su existencia. Bruna carece de pasado, y por tanto su identidad no puede construirse sobre el recuerdo de lo ya hecho. Tan solo la vivencia

\footnotetext{
45 Lo mismo ocurre en la película de Ridley Scott, donde nos encontramos con un "enfoque desencializante, desnaturalizador de la identidad, totalmente coherente con los presupuestos construccionistas y posmodernos” (Belmonte Arocha y Guillamón Carrasco 2005: 2-3).

46 De nuevo el guiño hacia Blade Runner es evidente: “en la película se intuye el desprecio romántico a la razón como principal especificidad humana [...] son los sentimientos y la memoria las facultades más fiables para determinar lo que es humano y lo que no lo es en un mundo dominado por la biotecnología” (Montes Pérez 2004: 303-304).
} 
del ahora la aleja de la locura y a la vez del determinismo que ya ha puesto fecha y hora a su final. Sin pasado, sin futuro y sin una esencia conformada nítidamente, la replicante usa como mecanismo supremo de rebeldía la intensa vivencia del día a día, mostrando así en última instancia unas ansias por vivir que solo pueden recluirse en el ahora. ${ }^{47}$

\section{Conclusiones}

La ciencia ficción en España está viviendo, sin duda, uno de sus mejores períodos. Así, las últimas décadas han sacado a la luz una más que notable producción en todos los ámbitos posibles, ${ }^{48}$ al tiempo que los tradicionales prejuicios apriorísticos de parte de la crítica están dejando paso a una nueva actividad académica tan fecunda como desacomplejada. Y es que este es sin duda un género que, por sus propias características, permite como pocos el desarrollo de temas más o menos anejos al ámbito de la filosofía, tales como la reflexión en torno al tiempo o la propia idea de identidad, a partir sobre todo de dos mecanismos fundamentales que confluyen en gran medida: el mundo de la virtualidad y el ámbito de los universos paralelos.

Tal y como apunta Aguilera (2014: 3), "la percepción del paso del tiempo nos hace humanos [...] El tiempo [...] acaba por encontrarnos y devolvernos una imagen certera de quiénes somos o

\footnotetext{
47 Tal y como apunta López-Pellisa (2015: 214), en realidad el elemento fundamental que diferencia Do Androids Dream of Electric Sheep? de la película de Ridley Scott -y, podríamos añadir, del relato de Montero- es el tratamiento de la figura del replicante. Así, mientras que en el texto del norteamericano los “andrillos" son fríos y violentos, sin que el lector experimente ninguna empatía hacia ellos, en Blade Runner - y en Lágrimas en la lluvia - "cobran un aspecto heroico", llevando a espectador y a lector, respectivamente, "hacia la posición de los replicantes, y los presenta como unos seres más humanos que los bumanos [...] Aparecen así como los esclavos proletarios de un mundo hipertecnologizado que los persigue y retira [...] simplemente por ser diferentes”.

48 Así, véase Moreno Serrano (2018) para lo tocante a la narrativa, López-Pellisa (2018c) a propósito del teatro, Sánchez Trigos (2018) en relación con el cine, Cascajosa Virino (2018) para la producción televisiva, Martínez (2018) para poesía y Trabado Cabado (2018) en relación con la narración gráfica.
} 
quiénes podemos llegar a ser para alcanzar nuestros sueños”. Como hemos podido ver, las dos obras analizadas - las cuales se apropian, en gran medida, de rasgos pertenecientes a los subgéneros del steampunk y del ciberpunk- se sirven del tiempo para construir de diferentes formas la idea de identidad. Así, en el caso de El mapa del tiempo uno de los elementos nucleares es la posibilidad de viajar en el tiempo - recurso narrativo frecuente en el steampunk-, lo cual lleva consecuentemente al desarrollo de universos paralelos. A partir de ahí, la narración configura toda una metáfora del tiempo en cuanto mapa con una serie de senderos que se bifurcan, llevando así a concebir la idea de libertad en cuanto capacidad de elección del sujeto, quien se enfrenta, con más o menos vértigo, a un camino que toma dos, o más, itinerarios posibles. Por ello, en el relato de Félix J. Palma la idea de identidad se resquebraja ante la presencia de múltiples yoes — cada uno de los cuales opta por un sendero diferente-, de entre los que hemos de escoger por necesidad tan solo a uno, lo cual lleva con frecuencia a una insatisfacción que emana de la inevitable fabulación “¿y si...?”

Frente a ello, el ciberpunk, y más particularmente Lágrimas en la lluvia, muestran una propuesta diferente. Así, la novela ofrece para la protagonista una visión desoladora y pesimista del tiempo basada en un pasado que no existe - como consecuencia de la constatación de que sus recuerdos son artificiales, lo que siembra una y otra vez la duda gnoseológica acerca de la memoria-, y que por tanto no permite construir una identidad propia que surja del continuo biográfico, y un futuro con clara fecha de caducidad, fruto del conocimiento del día (aproximado) de la muerte, lo que aboca a un inevitable determinismo. Por todo ello, el tiempo, inasible, aparece configurado como una suerte de microuniverso circunscrito en exclusiva al presente, lo que resquebraja la metáfora del devenir en cuanto flecha unidireccional. Ante todo ello, la identidad —vacía de pasado/recuerdos - solo puede surgir del ahora, y la belleza y el amor se convierten en los únicos mecanismos con los que intentar exorcizar un universo personal que carece de pasado y futuro. 
En conclusión, El mapa del tiempo y Lágrimas en la lluvia ofrecen dos muy interesantes - y diferentes- propuestas con las que reflexionar, desde el ámbito de la ciencia ficción, acerca de las nociones de identidad y de tiempo. Ojalá el camino andado por algunos de los narradores españoles en los últimos tiempos sirva para desposeer a parte de la crítica y de los lectores de unos prejuicios acerca de la literatura no realista basados, con frecuencia, en estereotipos alejados de una interpretación objetiva de la producción novelística actual.

\section{Referencias bibliográficas}

Aguilera, Manuela

2014 “Como lágrimas en la lluvia”. Crítica. 990, 3.

Amartin-Serin, Annie

1996 La création défiée. L’homme fabriqué dans la littérature. Paris: Presses Universitaires de France.

Areco, Macarena

2011 "Bestiario ciberpunk: sobre el imbunche y otros monstruos en Ygdrasil de Jorge Baradit". Aisthesis. 49, 163-174. Consultado: 9 de enero de 2019. <http://revistaaisthesis.uc.cl/index.php/ rait/article/view/312/294>

Arranz, David Felipe

2014 "La literatura de viajes en el tiempo: orígenes e hitos". Crítica. 990, 76-79.

BARCELó, Miquel

2009 "Los viajes en el tiempo en la literatura de ciencia ficción". En Los viajes en el tiempo. Un enfoque multidisciplinar. Eds., Enrique Alonso y Enrique Romerales. Madrid: Ediciones UAM, 29-50.

Belmonte Arocha, Jorge y Silvia Guillamón Carrasco

2005 "La representación del «otro-mujer» en las pantallas: contenidos fílmicos en televisión y co-educación”. Comunicar: Revista científica iberoamericana de comunicación y educación. XXV. 2, 1-6. 
Bordes Solanas, Montserrat

1998 "Filosofía en clave de ciencia ficción: las personas y sus condiciones de supervivencia en el tiempo". Teorema. XVII. 2, 59-75. Consultado: 19 de diciembre de 2018. <https://docs.google. $\mathrm{com} /$ viewer?url=https $\% 3 \mathrm{~A} \% 2 \mathrm{~F} \% 2 \mathrm{Fdialnet}$.unirioja.es $\% 2 \mathrm{~F}$ descarga \%2Farticulo\%2F2043691.pdf\&fname=Dialnet-FilosofiaEnClaveDeCienciaFiccion-2043691.pdf\&pdf=true>

Broncano, Fernando y David Hernández de la Fuente

2010 De Galatea a Barbie. Autómatas, robots y otras figuras de la construcción femenina. Madrid: Lengua de Trapo.

BRUNER, Jerome

1986 Realidad mental y mundos posibles. Los actos de la imaginación que dan sentido a la experiencia. Barcelona: Gedisa.

Cascajosa Virino, Concepción

2018 “Televisión 2000-2015”. En Historia de la ciencia ficción en la cultura española. Ed., Teresa López-Pellisa. Frankfurt am Main/Madrid: Vervuert/Iberoamericana, 357-380.

Conte Imbert, David

2011 "El mundo de las ciudades oscuras, de Schuiten y Peeters: una topografía de la desubicación”. Ángulo recto. Revista de estudios sobre la ciudad como espacio plural. III. 2, 247-277. Consultado: 20 de diciembre de 2018. <http://revistas.ucm.es/ index.php/ANRE/article/view/37588/36793>

Cuadros Contreras, Raúl

2008 "Reflexiones sobre alteridad y técnica: la figura del robot humanoide en algunas transposiciones de la literatura al cine". Revista CS. 2, 247-263.

Dick, Philip K.

1968 Do Androids Dream of Electric Sheep? New York: Doubleday. Díez, Julián

2008 "Secesión”. Hélice. Reflexiones críticas sobre ficción especulativa. 10, 5-11.

Dopazo Gallego, Antonio

2013 "El estoicismo a la luz de la noción de tiempo: Lógica, Física y Ética”. LOGOS. Anales del Seminario de Metafísica. 46, 183209. 
EsCANDEll Montiel, Daniel

2016 Mi avatar no me comprende. Cartografías de la suplantación y el simulacro. Madrid: Delirio.

FERNÁNDEZ, Laura

2011 "Llega por fin a España la novela «steampunk»". Consultado: 20 de diciembre de 2018. <http://www.siis.net/documentos/ hemeroteca/111206_12.pdf>

Foucault, Michel

2000 Los anormales. Buenos Aires: Fondo de Cultura Económica.

García, Cecilia

2014 "El cine, una máquina del tiempo". Crítica. 990, 71-75.

García-Borreguero, Paula

2014 "La percepción subjetiva del paso del tiempo". Crítica. 990, 66-70.

García Selgas, Fernando J.

1999 "El ciborg como reconstrucción del agente social”. Política y sociedad. 30, 165-191.

Garrido-Maturano, Ángel E.

2014 "El tiempo, el mar y las estrellas. Sentido cosmológico, filosófico y religioso del tiempo". Crítica. 990, 36-41.

GRANDE, Antonio

2014 "Por qué si perdemos los relojes no perdemos el tiempo: representaciones y prácticas culturales”. Crítica. 990, 57-61.

Grilli Silva, Javier

2016 "Cine de ciencia ficción y enseñanza de las ciencias. Dos escuelas paralelas que deben encontrarse en las aulas". Revista Eureka sobre Enseñanza y Divulgación de las Ciencias. XIII. 1, 137-148.

GuHL, Mercedes

2001 "Ciencia ficción para niños Made in América Latina". Cuadernos de Literatura Infantil y Juvenil. XIV. 139, 49-57.

Haraway, Donna

1991 “A Cyborg Manifesto: Science, Technology, and SocialistFeminism in the Late Twentieth Century". En Simians, 
Cyborgs and Women: The Reinvention of Nature. New York: Routledge, 149-181.

Hermann Acosta, Andrés

2012 "Ficcionalización, pensamiento, lenguaje y nuevas narrativas virtuales". Sophia. 12, 105-121. Consultado: 20 de diciembre de 2018. <https://www.redalyc.org/articulo. oa?id=441846101007>

Hesles SÁnchez, Germán J.

2013 El viaje en el tiempo en la literatura de ciencia ficción espanola. Madrid: Universidad Complutense de Madrid. Consultado: 19 de diciembre de 2018. <https://docs. google.com/viewer?url=http $\% 3 \mathrm{~A} \% 2 \mathrm{~F} \% 2 \mathrm{Feprints.ucm}$. es $\% 2$ F $21401 \% 2$ F1 \% 2FT34464.pdf\&fname $=$ T3 3464 . $\mathrm{pdf} \& \mathrm{pdf}=$ true $>$

Konstantinova, Iana

2017 "Posthumanism in Rosa Montero's Lágrimas en la lluvia and El peso del corazón”. Letras Hispanas. 13, 183-192.

LeONe, Maryanne L.

2017 "Trans-species Collaborations in Response to Social, Economic, and Environmental Violence in Rosa Montero's Lágrimas en la lluvia and El peso del corazón”. Ecozon@: European Journal of Literature, Culture and Environment. VIII. 1, 61-78. Consultado: 9 de enero de 2019. <https://docs. google.com/viewer?url=http $\% 3 \mathrm{~A} \% 2 \mathrm{~F} \% 2 \mathrm{Fecozona.eu} \% 2 \mathrm{Fa}$ rticle\%2FviewFile\%2F1040\%2F1554\&fname=1040-4200-1PB.pdf\&pdf=true $>$

López-Pellisa, Teresa

2015 Patologías de la realidad virtual. Madrid: Fondo de Cultura Económica.

López-Pellisa, Teresa

2017 "Alucinadas: Women Writers of Spanish Science Fiction". Science Fiction Studies. 44, 308-322. <https://doi.org/10.5621/ sciefictstud.44.2.0308>

LóPEz-PELLISA, Teresa

2018a Historia de la ciencia ficción en la cultura española. Frankfurt am Main/Madrid: Vervuert/Iberoamericana. 
LóPEZ-Pellisa, Teresa

2018b "Introducción: del inicio a la naturalización”. En Historia de la ciencia ficción en la cultura española. Ed., Teresa LópezPellisa. Frankfurt am Main/Madrid: Vervuert/Iberoamericana, 9-46.

López-Pellisa, Teresa

2018c “Teatro 1990-2015”. En Historia de la ciencia ficción en la cultura española. Ed., Teresa López-Pellisa. Frankfurt am Main/ Madrid: Vervuert/Iberoamericana, 251-278.

Martín, Sara y Fernando Ángel Moreno Serano

2017 "A Bibliography and Filmography of Spanish SF". Science Fiction Studies. XLIV. 2, 331-340.

Martín Rodríguez, Mariano

2013 "El retrofuturismo literario". En torno a Steampunk: Antología retrofuturista". Hélice. Reflexiones críticas sobre ficción especulativa. 2, 64-72.

Martín Rodríguez, Mariano

2016a "Estudios sobre literatura especulativa”. Hélice. Reflexiones críticas sobre ficción especulativa. 6, 31-62.

Martín Rodríguez, Mariano

2016b “Estudios sobre literatura especulativa II”. Hélice. Reflexiones críticas sobre ficción especulativa. 7, 43-67.

Martín Rodríguez, Mariano

2017a "Estudios sobre literatura especulativa. Complemento". Hélice. Reflexiones críticas sobre ficción especulativa. 8, 43-47.

Martín Rodríguez, Mariano

2017b “Rosa Montero". Hélice. Reflexiones críticas sobre ficción especulativa. 8, 63-72.

Martín Rodríguez, Mariano

2018 "Narrativa 1900-1953". En Historia de la ciencia ficción en la cultura española. Ed., Teresa López-Pellisa. Frankfurt am Main/Madrid: Vervuert/Iberoamericana, 71-122. 
MartínEZ, Xaime

2018 “Poesía 1900-2015”. En Historia de la ciencia ficción en la cultura española. Ed., Teresa López-Pellisa. Frankfurt am Main/ Madrid: Vervuert/Iberoamericana, 381-412.

Matangrano, Bruno Anselmi

2016 "O olhar contemporãneo na releitura do moderno: A liçã de anatomía do temivel Dr. Louison". Estudos de Literatura Brasileira Contemporãnea. 48, 247-280.

MERÁs, Lidia

2014 "Replicantes o sumisas: El cyborg femenino desde Blade Runner". Sesión no numerada: Revista de letras y ficción audiovisual. 4, 7-33. Consultado: 9 de enero de 2019. <https://docs.google.com/viewer?url=https \%3A \% $2 \mathrm{~F} \% 2 \mathrm{~F}$ dialnet.unirioja.es \% 2Fdescarga \% 2Farticulo\%2F4675470. pdf\&fname=Dialnet-ReplicantesOSumisasElCyborgFemeninoDesdeBladeRunne-4675470.pdf\&pdf=true>

Mesa Gancedo, Daniel

2002 Extraños semejantes. El personaje artificial y el artefacto narrativo en la literatura hispanoamericana. Zaragoza: Prensa Universitaria de Zaragoza.

Molina Porras, Juan

2018 "Los orígenes de la ciencia ficción en la narrativa española". En Historia de la ciencia ficción en la cultura española. Ed., Teresa López-Pellisa. Frankfurt am Main/Madrid: Vervuert/ Iberoamericana, 47-70.

Montero, Rosa

2016a El peso del corazón. Barcelona: Seix Barral.

Montero, Rosa

2016b Lágrimas en la lluvia. Barcelona: Seix Barral.

Montero, Rosa

2018 Los tiempos del odio. Barcelona: Seix Barral.

Montes Pérez, Carlos

2004 "El elogio de la memoria y el paraíso recobrado: Identidad, biotecnología y antropología en Blade Runner". Thémata. Revista de Filosofía. 33, 299-304. 
Montesdeoca, Raúl

2013 La máquina del juicio final. Salamanca: Dlorean Ediciones.

Moreno Serrano, Fernando Ángel

2007 "Notas para una historia de la ciencia ficción en España". Dicenda. Cuadernos de Filología Hispánica. 25, 125-138. Consultado: 19 de diciembre de 2018. <https://docs.google.com/ viewer?url=http $\% 3 \mathrm{~A} \% 2 \mathrm{~F} \% 2$ Frevistas.ucm.es $\% 2$ Findex.php \%2FDICE\%2Farticle\%2Fdownload\%2FDICE0707110125 A\%2F11811\&fname=12658-12738-1-PB.PDF\&pdf=true >

Moreno Serrano, Fernando Ángel

2010 Teoría de la literatura de Ciencia Ficción. Poética y Retórica de lo Prospectivo. Vitoria: PortalEditions.

Moreno Serrano, Fernando Ángel

2013

"Hard y Prospectiva: Dos poéticas de la ciencia ficción". Hélice. Reflexiones críticas sobre ficción especulativa. 2, 5-16.

Moreno Serrano, Fernando Ángel y Cristina PÉREZ

2017 "An Overview of Spanish Science Fiction". Science Fiction Studies. 44, 216-228. <https://doi.org/10.5621/ sciefictstud.44.2.0216>

Moreno Serrano, Fernando Ángel

2018 "Narrativa 2000-2015". En Historia de la ciencia ficción en la cultura española. Ed., Teresa López-Pellisa. Frankfurt am Main/Madrid: Vervuert/Iberoamericana, 177-195.

Muñoz Corcuera, Alfonso

2009 "Realidad virtual y memorias posibles: apuntes sobre la presencia de mundos virtuales en el cine postmoderno de ciencia-ficción”. Eikasia. Revista de Filosofía. IV. 24, 1-10. Consultado: 20 de diciembre de 2018. <http://revistadefilosofia.com/24-21.pdf>

Palardy, Diana Q.

2018 The Dystopian Imagination in Contemporary Spanish Literature and Film. Youngstown: Palgrave MacMillan.

Palma, Félix J.

2009 El mapa del tiempo. Madrid: Alianza. 
Palma, Félix J.

2012 El mapa del cielo. Barcelona: Plaza \& Janés.

Palma, Félix J.

2014 El mapa del caos. Barcelona: Plaza \& Janés.

Pardo-Fernández, Rodrigo

2017 "Los límites de la otredad en Lágrimas en la lluvia, de Rosa Montero". La Colmena. 93, 31-39. Consultado: 9 de enero de 2019. <https://docs.google.com/viewer?url=ht tps $\% 3 \mathrm{~A} \% 2 \mathrm{~F} \% 2 \mathrm{Fdialnet}$ unirioja.es $\% 2 \mathrm{Fdescarga} \% 2 \mathrm{Far}$ ticulo\%2F6093582.pdf\&fname=Dialnet-LosLimitesDeLaOtredadEnLagrimasEnLaLluviaDeRosaMon-6093582. pdf\&pdf=true $>$

Pedraza, Pilar

1998 Máquinas de amar. Madrid: Valdemar.

Pegoraro, Éverly

2013 "Steampunk in Brazil: Visuality and Sociability in an Urban Retro-Futuristic Culture". International Journal of Communication. 7, 1852-1863. Consultado: 20 de diciembre de 2018. <https://ijoc.org/index.php/ijoc/article/ viewFile/2183/974>

Portero, Aixa y Agustín Linares

2013 "Casos de arte contemporáneo como proceso de ciborgización de la sociedad". Teknokultura. Revista de Cultura Digital y Movimientos Sociales. 10, 375-397.

Prado Feliu, José Ignacio

1998 Mi(l) lent(s). Madrid: Libertarias.

Prieto Hames, Pablo

2016 "La poética del tiempo: una aproximación al imaginario steampunk". Ucoarte. Revista de Teoría e Historia del Arte. 5, 95-115. Consultado: 20 de diciembre de 2018. <https://doi. org/10.21071/ucoarte.v5i0.9555>

Ramos, Josué

2013 Lendaria. Salamanca: Dlorean Ediciones.

REMESAR, Joseph

2013 El dirigible. Salamanca: Dlorean Ediciones. 
RÍO PARRA, Elena del

2003 Una era de monstruos: representaciones de lo deforme en el Siglo de Oro español. Madrid: Editorial Iberoamericana.

SALLES, Ricardo

2002 “Tiempos, objetos y sucesos en la metafísica estoica”. DIÁNOIA. XLVII. 49, 3-22.

SÁNCHEZ, Guillem y Eduardo GALlego

2003 “¿Qué es la ciencia-ficción?” SdCF. Sitio de Ciencia-Ficción. Consultado: 19 de marzo de 2019. <https://www.ciencia-ficcion.com/opinion/op00842.htm>

SÁNChEZ Trigos, Rubén

2018 “Cine 1980-2015”. En Historia de la ciencia ficción en la cultura española. Ed., Teresa López-Pellisa. Frankfurt am Main/ Madrid: Vervuert/Iberoamericana, 301-326.

Sánchez Usanos, David

2009 "A través del espejo. ¿De qué hablamos cuando hablamos de «viajes en el tiempo»?” En Los viajes en el tiempo. Un enfoque multidisciplinar. Eds., Enrique Alonso y Enrique Romerales. Madrid: Ediciones UAM, 155-168.

SANZ, Irene

2017 "Human and Nonhuman Intersections in Rosa Montero's Bruna Husky Novels”. Science Fiction Studies. 44, 323-330. $<$ https://doi.org/10.5621/sciefictstud.44.2.0323>

SHelley, Mary

1818 Frankenstein; or, The Modern Prometheus. London: Lackington, Hughes, Harding, Mavor \& Jones.

Steimberg, Alejo

2016 La realidad bajo ataque. La resurrección de lo fantástico en la ciencia ficción ontológica de Philip K. Dick. Cáceres: Universidad de Extremadura. Consultado: 20 de diciembre de 2018. <http://dehesa.unex.es/xmlui/bitstream/handle/10662/3884/ TDUEX_2016_Steimberg.pdf? sequence=4\&isAllowed=y>

Trabado Cabado, José Manuel

2018 “La narración gráfica 1900-2015”. En Historia de la ciencia ficción en la cultura española. Ed., Teresa López-Pellisa. 
Frankfurt am Main/Madrid: Vervuert/Iberoamericana, 413478.

Tur Planells, Helena

2004-2006 "Reflexiones sobre la figura del monstruo". Tropelías. Revista de Teoría de la Literatura y Literatura Comparada. 15-17, 699-716.

Udías Vallina, Agustín

2014 “El tiempo: una cuestión siempre abierta”. Crítica. 990, 24-29.

Uribe Aguilar, Sebastián

2008 "Imagen de un cyborg o un humano aparente: Propuesta reflexiva a partir de la lectura en paralelo del Manifiesto Cyborg y Blade Runner”. Iconofacto. IV. 5, 99-113.

VAQUERIZO, Eduardo

2005 Danza de Tinieblas. Barcelona: Ediciones Minotauro.

Velázquez Castro, Marcel

2017 "El monstruo como dispositivo cultural múltiple y complejo". A contracorriente. Una revista de estudios latinoamericanos. XV. 1, 341-346.

VIZCARRA, Fernando

2011 "Modernidades múltiples y perfiles identitarios en Blade Runner. Un ejercicio de análisis textual cinematográfico”. Culturales. VII. 13, 31-62.

ZĂHAN, Dana

2011 "The paradox of time in Stoic education". Ontology Studies. 11, 29-37.

Recepción: 16/05/2019 Aceptación: 16/06/2020 